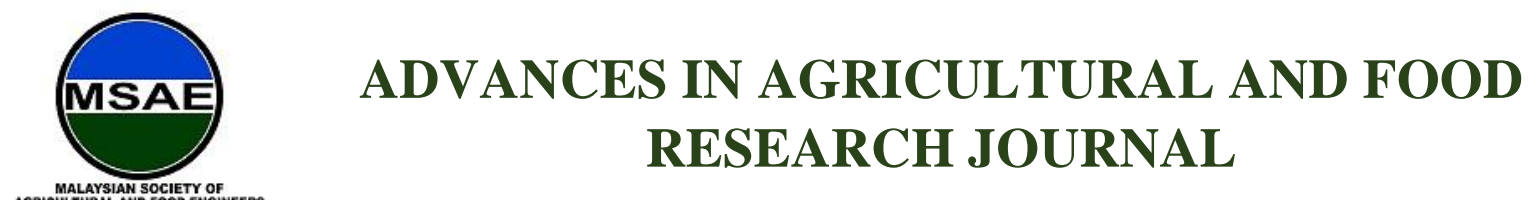

HH PUBLISHER

Review Article

\title{
Quality Inspection of Food and Agricultural Products using Artificial Intelligence
}

\author{
Maimunah Mohd Ali ${ }^{1}$, Norhashila Hashim ${ }^{1,3 *}$, Samsuzana Abd Aziz ${ }^{1,3}$, Ola Lasekan ${ }^{2}$ \\ ${ }^{1}$ Department of Biological and Agricultural Engineering, Faculty of Engineering, Universiti Putra Malaysia, \\ 43400, Serdang, Selangor, Malaysia \\ ${ }^{2}$ Department of Food Technology, Faculty of Food Science and Technology, Universiti Putra Malaysia, 43400 \\ UPM, Serdang, Selangor, Malaysia \\ ${ }^{3}$ SMART Farming Technology Research Centre, Faculty of Engineering, Universiti Putra Malaysia, 43400 \\ UPM, Serdang, Selangor, Malaysia \\ *Corresponding author: Norhashila Hashim, Department of Biological and Agricultural Engineering, Faculty \\ of Engineering, Universiti Putra Malaysia, 43400, Serdang, Selangor, Malaysia; norhashila@upm.edu.my
}

\begin{abstract}
A rising awareness for quality inspection of food and agricultural products has generated a growing effort to develop rapid and non-destructive techniques. Quality detection of food and agricultural products has prime importance in various stages of processing due to the laborious processes and the inability of the system to measure the whole of the food production. The detection of food quality has previously depended on various destructive techniques that require sample destruction and a large amount of postharvest losses. Artificial Intelligence (AI) has emerged with big data technologies and high-performance computation to create new opportunities in the multidisciplinary agri-food domain. This review presents the key concepts of AI comprising an expert system, artificial neural network (ANN), and fuzzy logic. A special focus is laid on the strength of AI applications in determining food quality for producing high and optimum yields. It was demonstrated that ANN provides the best result for modelling and effective in real-time monitoring techniques. The future use of AI for assessing quality inspection is promising which could lead to a real-time as well as rapid evaluation of various food and agricultural products.
\end{abstract}

Keywords: artificial intelligence; quality inspection; food products; agriculture; nondestructive

Received: $12^{\text {th }}$ March 2021

Received in revised form: $17^{\text {th }}$ July 2021

Accepted: $3^{\text {rd }}$ August 2021

Available Online: $23^{\text {rd }}$ August 2021

Citation: Mohd Ali, M., Hashim, N., Abd Aziz, S. et al. Quality inspection of food and agricultural products using artificial intelligence. Adv Agri Food Res J 2021; 2(2): a0000237. https://doi.org/10.36877/aafrj.a0000237 


\section{Introduction}

The recent advances in the digitisation technologies in food industries have led to a dramatic transformation all over the world. Artificial intelligence (AI) has played a key role in daily lives by building vast domain technology which acts as a human brain (Talaviya et $a l ., 2020)$. This tool is executed by observing the functions of the human brain in decisionmaking and solving problems with the assistance of intelligent software and devices. In this case, these intelligent devices are stored with training datasets which further produce the desired output, similar to how the human brain works. The expansion of digital technology has opened up AI-driven data analytic opportunities which has led to decision making and automated data collection (How et al., 2020). For instance, the utilisation of AI is essential for assisting humans through probabilistic reasoning and establishment of predictive modelling. The exploration of these techniques has demonstrated a simplistic approach that can be interpreted from the augmentation of human cognitive capabilities (Sharma et al., 2020). Over the years, AI has been used in the quality evaluation of various food and agricultural products due to the rising food demand of the world in line with the development of modern technologies. Along with other emerging concepts of modern technologies, the use of AI has evolved as one of the promising techniques in solving the need for food quality evaluation using a computer system. In this sense, AI serves as a powerful and wide-ranging tool coupled with advanced techniques including cloud computing and big data (Sun et al., 2019).

In terms of food quality inspection, tedious analysis and sample destruction are the biggest concerns when monitoring the quality and shelf-life of food products (Hussain et al., 2018). Practically, the determination of food quality requires a rapid, efficient, and accurate analysis. Data analysis from the measurement of food attributes is very important due to the fact that a large number of datasets may contain irrelevant and redundant information. As a result of going digital, the use of AI an impactful analytic tool was found suitable for quality inspection of various food and agricultural products. The core of AI consists of machine learning and deep learning (Bresilla et al., 2019). Machine learning is widely used in the quality inspection of food products, especially for classification and predictive modelling such as partial least squares (PLS), support vector machine (SVM), artificial neural network (ANN), k-nearest neighbour ( $\mathrm{kNN}$ ), and random forest (Zhou et al., 2019). The study by Castro et al. (2019) described that machine learning algorithms provided better performance in the fruit classification according to the respective maturity stages. On the other hand, deep learning has also gained attention in quality evaluation of food attributes due to the ability of learning data representation. Deep learning has been implemented into numerous quality detection systems for food products including apples (Kang \& Chen, 2020), butter (Kang \& Chen, 2020), tomatoes (Liu et al., 2019), grapes (Santos et al., 2020), olive oil (Izquierdo et al., 2020), and meat (Al-Sarayreh et al., 2018).

With the advent of AI, many applications in food-related tasks have shown to a great extent on the need for data processing which can provide detailed information from different 
types of food samples. Nowadays, much effort has been performed in the direction of different AI approaches to solve the bottlenecks of analytical techniques in determining food quality. Data fusion using AI approaches can improve the performance of analytical methods in order to evaluate the quality of food samples. In this context, food quality inspection is conducted using AI-driven tools comprising of various steps including data pre-processing, data fusion, feature extraction, and model development (Srivastava \& Sadistap, 2018). AI offers an alternative solution in food quality inspection with the benefits of adaptive ability, model robustness, and self-learning ability. Thus, this paper presents a comprehensive overview of the key concepts of AI technologies including expert system, ANN, and fuzzy logic. The applications of AI in the quality inspection of various food and agricultural products are also outlined with emphasis on the technical inventions behind non-destructive techniques.

\section{Key Concepts of AI}

AI is likely to transform food demand as this technology can be applied to monitor the quality inspection of food and agricultural products within a limited time frame. The better prospect for digital transformation in terms of food quality detection can be addressed to highlight the underlying principles and technological advancement of AI. This section covers the fundamental aspects of AI consisting of expert system, ANN, and fuzzy logic which can be implemented in various ways in order to reduce human effort and the need for intervention.

\subsection{Expert System}

Expert system is a part of an AI system that brings professional experience and the capability of solving complex problems using reasoning ability and knowledge representation (Eli-Chukwu, 2019). It can be separated into several types, namely, rule-based expert system, frame-based expert system, semantic network expert system, and logical album expert system based on the knowledge representation (Sun et al., 2019). On the other hand, the general form of expert system consists of knowledge acquisition, knowledge base, human-machine interface, dynamic database, inference engine, and interpreter. In this sense, the manner of expert thinking through knowledge information is simulated based on the problem-solving step of the expert system.

The development of expert system operating in ordinary devices has taken place with the improvement of a small set of variables by taking into account various considerations based on prediction performance (Duong et al., 2020). In the research work conducted by Azarmdel et al. (2020), the grading of mulberry fruit based on the maturity level was investigated using an expert system as the assessment method for the image processing method. Feature selection based on colour, texture, and geometric features were obtained which resulted in the classification accuracy of $100 \%$ for maturity estimation of the fruit. Duong et al. (2020) developed an expert system using two deep neural network architectures, 
namely EfficientNet and MixNet for fruit recognition. Both architectures successfully improved the overall classification accuracy up to $95 \%$ as compared to a well-established baseline. It is necessary to ascertain the specific development of expert systems to ensure their commercial use for the quality inspection of food and agricultural products. Practically, the performance of an expert system is evaluated according to the pacing, the monitoring process, and automatic detection. Thus, the implementation of an expert system should be well-defined for accuracy and speed to synchronise with the availability of input functions.

\subsection{ANN}

In AI applications, ANNs are the most widely used method for food quality detection purposes. An ANN is a form of mathematical model based on linear or non-linear processing features known as a node (Sun et al., 2019). Theoretically, the electric signal navigates via neurons with the aid of axons according to an inter-linked neural network in which the synapses at the tip of each node passes through the signal (Jha et al., 2019). The working principle of ANN is similar to the human brain that notifies the system to operate pertaining to an in-built task as an alternative to the conventional computational task. The fundamental architecture of ANN comprises three main layers which are the input layer, hidden layer, and output layer (Figure 1). The input layer obtains the data from the architecture which will then be connected to the hidden layer to process the raw information. The obtained information is further sent to the output layer connected by the nodes to create the final output. The main benefits of ANN layers are in the ability to predict the base of parallel reasoning as well as to train the neural networks efficiently. Generally, ANN can be identified by a learning algorithm, neuron model, and architecture to specify the pattern relationship between the neurons and different layers.

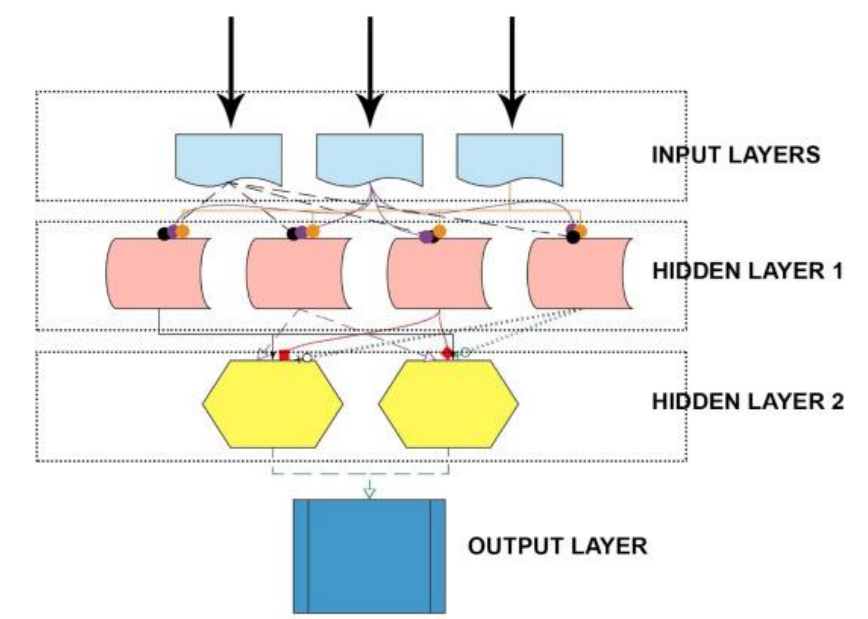

Figure 1. Artificial neural network layers (Jha et al., 2019).

Previous works have reported on the feasibility of ANN in evaluating the food quality of food and agricultural products such as potatoes (Rady et al., 2015), coconuts (Caladcad et al., 2020), durians (Kumar et al., 2017), and olive oil (Sanaeifar \& Jafari, 2019). Kumar et al. (2017) investigated the leaf estimation of durian using the ANN model. The ANN model 
consists of two input layers, one hidden layer, and one output layer with the best fitting results of coefficient of determination $\left(\mathrm{R}^{2}\right)$ of 0.96 and mean absolute error of 2.41. Sanaeifar and Jafari (2019) reported on the potential of dielectric spectroscopy to evaluate the oxidative stability index of olive oil. In this study, the ANN method was used to obtain the oxidative stability prediction with $R^{2}$ of 0.98 . With the advantages of efficiency and simplicity of ANN, it is considered a superior tool to model dynamic and complicated tasks in food quality detection. The ANN models that are commonly used for monitoring food quality inspection are the feed-forward neural network and the feed-back neural network (Cheng \& Sun, 2015). Furthermore, the ANN model can be trained in such a way that the non-linear regression can be transformed into linear regression, which signifies a huge potential for dealing with complex correlation problem. In the practical applications of using ANN models for the evaluation of food quality, it is essential to look for effective methods to access the predictability and practicality in order to validate the established models.

\subsection{Fuzzy Logic}

Another field of AI is fuzzy logic which was developed by simulating the decision making and reasoning ability from the human brain consisting of fuzzy inference, fuzzification, fuzzy rule base, and defuzzification (Sun et al., 2019). The fuzzy interference knowledge is deciphered into a fuzzy rule base as the working principle of the fuzzy logic (Figure 2). After performing fuzzy processing, the input signal is converted into fuzzy input in order to obtain fuzzy conclusions. Meanwhile, the fuzzy interference is retrieved by generating the input degree based on the fuzzy rules for the synthesis regulation. From this, the system provides specific output data once the defuzzification of the fuzzy conclusions is complete. In fuzzy logic, the relationship between inputs and outputs is signified by 'if-then' rule statements resulting from the defuzzification step (Kanade \& Shaligram, 2018). The techniques that are widely used for the defuzzification step are central mean, maximum criterion method, and centre of gravity.

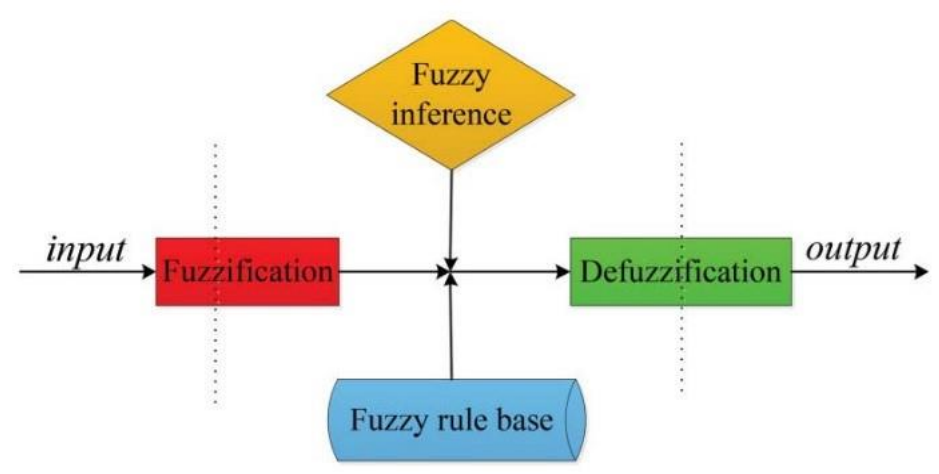

Figure 2. Schematic diagram of fuzzy logic (Sun et al., 2019).

In order to solve the issue of writing code for a particular program to be used in the food quality inspection, fuzzy logic saves the time and effort related to the feature specification. New technologies have been established based on fuzzy logic applications in 
various food quality detection including sorting of orange (Jhawar, 2016), determination of moisture content in olive oil (Ortega et al., 2016), guava grading based on ripening stages (Kanade \& Shaligram, 2018), and maturity estimation of bell peppers (Villaseñor-Aguilar et $a l ., 2020)$. Kanade and Shaligram (2018) integrated the electronic nose sensor with fuzzy logic to classify guava according to the maturity levels. The results retrieved from the fuzzy logic module generated classification accuracy of $90 \%$ for the maturity estimation of guava fruit. Similarly, Villaseñor-Aguilar et al. (2020) determined the maturity stages of bell pepper using fuzzy logic system based on the prediction of total soluble solids. An accuracy of $88 \%$ was obtained using fuzzy logic models in classifying four maturity stages of bell pepper. Suksawat and Komkum (2015) used a fuzzy logic system for the grading of pineapple quality at three different varieties. The outcomes for the fruit grading obtained the accuracy of $88 \%$ and relative error of $2.3 \%$ based on the size inspection. Fuzzy logic has demonstrated a good representation as a control system, especially for dealing with complex procedures for the quality detection of food and agricultural products. The data fusion of simple linguistic variables and algorithms could also be created from the mathematical expression of the fuzzy logic system.

\section{Applications of AI in Quality Determination of Food and Agricultural Products}

The current quality inspection of food and agricultural products is commonly evaluated by analytical method which is time-consuming and subjective. The rigorous development related to AI applications has evolved in terms of improvement in computation power of software and devices since consumers are willing to pursue good-quality food products (Venugopal \& Gopakumar, 2017). This section focuses on the recent applications using AI systems for the quality detection of food and agricultural products which are summarised in Table 1.

Table 1. Applications of AI in quality inspection of various food and agricultural products.

\begin{tabular}{|c|c|c|c|c|}
\hline Technology & Product & Aim & Results & References \\
\hline ANN & Mango & $\begin{array}{l}\text { Estimation of } \\
\text { dry matter } \\
\text { content }\end{array}$ & $\begin{array}{l}\text { ANN model was } \\
\text { satisfactory in all } \\
\text { categories }\end{array}$ & $\begin{array}{l}\text { Anderson } \text { et al. } \\
\text { (2021) }\end{array}$ \\
\hline ANN & Sugarcane & $\begin{array}{l}\text { Stalk content } \\
\text { prediction }\end{array}$ & Relative errors of $3 \%$ & $\begin{array}{l}\text { Guedes et al. } \\
(2020)\end{array}$ \\
\hline ANN & Fried fish & $\begin{array}{l}\text { Correlation } \\
\text { between } \\
\text { temperature, } \\
\text { time, oil } \\
\text { amount, and } \\
\text { nutritional } \\
\text { values }\end{array}$ & $\begin{array}{l}\text { ANN model } \\
\text { successfully tuned the } \\
\text { cooking parameters }\end{array}$ & $\begin{array}{l}\text { Sadhu et al. } \\
\text { (2020) }\end{array}$ \\
\hline ANN, SVM & $\begin{array}{l}\text { Cape } \\
\text { gooseberry } \\
\text { fruit }\end{array}$ & $\begin{array}{l}\text { Ripeness } \\
\text { classification }\end{array}$ & $\begin{array}{l}\text { SVM classifier showed } \\
\text { the highest f-measure }\end{array}$ & $\begin{array}{l}\text { Castro et al. } \\
(2019)\end{array}$ \\
\hline $\mathrm{CNN}$ & Rice flour & $\begin{array}{l}\text { Food } \\
\text { classification }\end{array}$ & Accuracies above $98 \%$ & $\begin{array}{l}\text { Estrada-Pérez } \\
\text { et al. (2021) }\end{array}$ \\
\hline
\end{tabular}




\begin{tabular}{|c|c|c|c|c|}
\hline Technology & Product & Aim & Results & References \\
\hline CNN & Tea shoot & $\begin{array}{l}\text { and } \\
\text { adulterations } \\
\text { Maturity } \\
\text { estimation }\end{array}$ & $\begin{array}{l}\text { Testing dataset obtained } \\
\text { accuracy of } 0.68\end{array}$ & $\begin{array}{l}\text { Chen and Yan } \\
(2020)\end{array}$ \\
\hline $\mathrm{CNN}$ & Bread crust & $\begin{array}{l}\text { Classification } \\
\text { of browning } \\
\text { degree during } \\
\text { baking }\end{array}$ & $\begin{array}{l}\text { Correct prediction } \\
\text { higher than } 99 \% \text { for all } \\
\text { classes }\end{array}$ & $\begin{array}{l}\text { Cotrim et al. } \\
(2020)\end{array}$ \\
\hline $\mathrm{CNN}$ & $\begin{array}{l}\text { Extra } \\
\text { virgin olive } \\
\text { oil }\end{array}$ & Adulteration & $\begin{array}{l}\text { Classification accuracy } \\
\text { ranged from } 97 \text { to } 100 \%\end{array}$ & $\begin{array}{l}\text { Izquierdo et al. } \\
\text { (2020) }\end{array}$ \\
\hline $\mathrm{CNN}$ & Sour lemon & Fruit grading & Accuracy of $100 \%$ & $\begin{array}{l}\text { Jahanbakhshi } \\
\text { et al. }(2020)\end{array}$ \\
\hline $\mathrm{CNN}$ & Kiwifruit & Fruit detection & Accuracy of $90 \%$ & $\begin{array}{l}\text { Liu et al. } \\
(2020)\end{array}$ \\
\hline CNN & Litchi & $\begin{array}{l}\text { Cultivar } \\
\text { classification }\end{array}$ & Accuracy of $84 \%$ & $\begin{array}{l}\text { Osako et al. } \\
(2020)\end{array}$ \\
\hline CNN & $\begin{array}{l}\text { Black goji } \\
\text { berry }\end{array}$ & $\begin{array}{l}\text { Determination } \\
\text { of chemical } \\
\text { compositions }\end{array}$ & $\begin{array}{l}\text { Obtained good } \\
\text { performances compared } \\
\text { to conventional } \\
\text { methods }\end{array}$ & $\begin{array}{l}\text { Zhang et al. } \\
(2020)\end{array}$ \\
\hline $\mathrm{CNN}$ & Wheat & $\begin{array}{l}\text { Identification } \\
\text { of the number } \\
\text { of wheat spikes }\end{array}$ & $\begin{array}{l}\text { Accuracy of overall } \\
\text { treatments did not } \\
\text { change significantly }\end{array}$ & $\begin{array}{l}\text { Sadeghi- } \\
\text { Tehran et al. } \\
\text { (2019) }\end{array}$ \\
\hline CNN & Peach & $\begin{array}{l}\text { Detection of } \\
\text { early decay }\end{array}$ & $\begin{array}{l}\text { Disease infection } \\
\text { symptom at a detection } \\
\text { rate of } 97 \%\end{array}$ & $\begin{array}{l}\text { Sun et al. } \\
(2019)\end{array}$ \\
\hline $\mathrm{CNN}$ & Guava & $\begin{array}{l}\text { Maturity } \\
\text { estimation }\end{array}$ & $\begin{array}{l}\text { Accuracy of } 100 \% \text { for } \\
140 \text { training data and } 20 \\
\text { epochs }\end{array}$ & $\begin{array}{l}\text { Sunarya et al. } \\
\text { (2019) }\end{array}$ \\
\hline $\mathrm{CNN}$ & Meat & Adulteration & $\begin{array}{l}\text { Classification accuracy } \\
\text { of } 94 \%\end{array}$ & $\begin{array}{l}\text { Al-Sarayreh et } \\
\text { al. (2018) }\end{array}$ \\
\hline DCNN & Strawberry & $\begin{array}{l}\text { Recognition of } \\
\text { two classes } \\
\text { (mature and } \\
\text { immature) }\end{array}$ & $\begin{array}{l}\text { Classification } \\
\text { accuracies of } 88 \% \\
\text { (mature) and } 77 \%, \\
\text { (immature) }\end{array}$ & $\begin{array}{l}\text { Habaragamuwa } \\
\text { et al. (2018) }\end{array}$ \\
\hline DCNN & Plum & $\begin{array}{l}\text { Variety } \\
\text { classification }\end{array}$ & $\begin{array}{l}\text { Accuracy values ranged } \\
\text { from } 91 \text { to } 97 \%\end{array}$ & $\begin{array}{l}\text { Rodríguez et } \\
\text { al. (2018) }\end{array}$ \\
\hline Fuzzy logic & Bell pepper & $\begin{array}{l}\text { Maturity } \\
\text { estimation }\end{array}$ & Accuracy of $88 \%$ & $\begin{array}{l}\text { Villaseñor- } \\
\text { Aguilar } \text { et al. } \\
\text { (2020) }\end{array}$ \\
\hline $\begin{array}{l}\text { Logistic } \\
\text { regression, } \\
\text { naïve Bayes }\end{array}$ & Maize & $\begin{array}{l}\text { Identification } \\
\text { of progeny } \\
\text { genotypes }\end{array}$ & $\begin{array}{l}\text { Overall prediction } \\
\text { accuracy ranged from } \\
78 \text { to } 87 \%\end{array}$ & $\begin{array}{l}\text { Seka et al. } \\
\text { (2019) }\end{array}$ \\
\hline $\begin{array}{l}\text { Machine } \\
\text { learning }\end{array}$ & Coconut & $\begin{array}{l}\text { Maturity level } \\
\text { detection }\end{array}$ & $\begin{array}{l}\text { Classification accuracy } \\
\text { of } 80 \%\end{array}$ & $\begin{array}{l}\text { Caladcad et al. } \\
\text { (2020) }\end{array}$ \\
\hline $\begin{array}{l}\text { Machine } \\
\text { learning }\end{array}$ & Tomato & $\begin{array}{l}\text { Defect } \\
\text { discrimination } \\
\text { and grading }\end{array}$ & $\begin{array}{l}\text { Highest accuracy of } \\
0.971\end{array}$ & $\begin{array}{l}\text { Ireri et al. } \\
(2019)\end{array}$ \\
\hline
\end{tabular}




\begin{tabular}{|c|c|c|c|c|}
\hline Technology & Product & Aim & Results & References \\
\hline $\begin{array}{l}\text { Machine } \\
\text { learning }\end{array}$ & Rice & $\begin{array}{l}\text { Variety } \\
\text { identification }\end{array}$ & $\begin{array}{l}\text { Classification accuracy } \\
\text { of } 87 \%\end{array}$ & $\begin{array}{l}\text { Qiu } \text { et al. } \\
(2018)\end{array}$ \\
\hline $\begin{array}{l}\text { Mask } \\
\text { region- } \\
\text { based CNN }\end{array}$ & Banana & $\begin{array}{l}\text { Classification } \\
\text { of banana tiers }\end{array}$ & $\begin{array}{l}96 \% \text { for overall } \\
\text { accuracy }\end{array}$ & Le et al. (2019) \\
\hline $\begin{array}{l}\text { Particle } \\
\text { least } \\
\text { squares }\end{array}$ & Apple & $\begin{array}{l}\text { Prediction of } \\
\text { soluble solid } \\
\text { content }\end{array}$ & $\begin{array}{l}\text { Prediction accuracy of } \\
0.990\end{array}$ & $\begin{array}{l}\text { Bai et al. } \\
\text { (2019) }\end{array}$ \\
\hline R-CNN & Citrus fruit & $\begin{array}{l}\text { Immature fruit } \\
\text { detection }\end{array}$ & Accuracy of $96 \%$ & $\begin{array}{l}\text { Gan et al. } \\
(2020)\end{array}$ \\
\hline R-CNN & Blueberry & $\begin{array}{l}\text { Fruit } \\
\text { quantification }\end{array}$ & $\begin{array}{l}\text { Classification rate of } \\
0.726\end{array}$ & $\begin{array}{l}\text { Gonzalez et al. } \\
\text { (2019) }\end{array}$ \\
\hline SVM & Green tea & $\begin{array}{l}\text { Classification } \\
\text { modelling }\end{array}$ & $\begin{array}{l}\text { Combining the textural } \\
\text { and spectral information } \\
\text { improved tea } \\
\text { classification }\end{array}$ & $\begin{array}{l}\text { Mishra et al. } \\
\text { (2019) }\end{array}$ \\
\hline
\end{tabular}

ANN, artificial neural network; DCNN, deep convolutional neural network; CNN, convolutional neural network; R-CNN, Region-based convolutional neural network; SVM, support vector machine.

AI has been proposed over the past few years for the quality assessment of various food and agricultural products. Qiu et al. (2018) used hyperspectral imaging coupled with convolutional neural network $(\mathrm{CNN})$ to detect four different types of rice cultivars. It was revealed that the CNN model showed promising results in evaluating the spectral data analysis with an improvement in the number of training samples. Habaragamuwa et al. (2018) studied the fruit recognition of mature and immature strawberries using the deep convolutional neural network (DCNN) approach under natural lighting conditions. Similarly, Rodríguez et al. (2018) identified plum varieties at an early stage using DCNN with a classification accuracy ranging from 91 to $97 \%$. In terms of meat products, Al-Sarayreh et al. (2018) studied the adulteration of meat by using CNN and SVM models. The findings demonstrated that the CNN model obtained the best overall classification accuracy of $94 \%$ compared to the SVM model. A study conducted by Sun et al. (2019) indicated that the CNN model had successfully identified a fungal infection in peaches with a detection rate of $97 \%$. Castro et al. (2019) classified Cape gooseberry fruit samples according to the ripeness level using machine learning methods. Several classifiers were selected (SVM, decision tree, and k-nearest neighbour) to determine the f-measure based on the colour space system.

Mishra et al. (2019) demonstrated an excellent performance of green tea classification using SVM models by integrating spectral and textural information during modelling. Le et al. (2019) examined the classification of banana tiers using a region-based convolutional neural network (R-CNN) in image recognition step. The study obtained an overall accuracy of $96 \%$ with the data augmentation rather than tedious multiple size features. In another approach, Bai et al. (2019) investigated the soluble solid content prediction in apples using a partial least squares model with a prediction accuracy of 0.990. Sadeghi-Tehran et al. (2019) identified the number of wheat spikes using a CNN model. It was signified that the accuracy 
of overall nitrogen treatments did not change significantly at different maturity stages. Gonzalez et al. (2019) developed R-CNN model for the quantification of blueberries via several CNN architectures with the best classification rate of 0.726. Another successful application of an AI application was for the identification of progeny genotypes in maize as reported by Seka et al. (2019). The maize samples were tested using Gaussian Naïve Bayes and Logistic Regression with an overall prediction accuracy ranging from 78 to $87 \%$.

Ireri et al. (2019) evaluated defect discrimination and grading of tomatoes using the SVM model during the postharvest process. The study successfully obtained the highest overall accuracy of 0.971 for the discrimination of healthy and defective tomatoes. Sunarya et al. (2019) determined the maturity estimation of guava fruits using the CNN method. Based on the LeNet architecture, a classification accuracy of $100 \%$ for 140 training data and 20 epochs was achieved. In recent studies by Anderson et al. (2021), the dry matter content prediction of mango was measured using ANN model, leading to the attainment of satisfactory results in all parameters (prediction statistics, model build speed, and prediction speed). Estrada-Pérez et al. (2021) reported on the application of CNN model to detect adulteration in rice flour. It was signified that the CNN model was able to identify the potential adulteration in rice flour with accuracies above $98 \%$. In a similar vein, Jahanbakhshi et al. (2020) discussed the feasibility of CNN algorithm to identify the defects in sour lemons with excellent accuracy of $100 \%$. Based on the method, the CNN model was evaluated for the classification of healthy and damaged sour lemons (Figure 3). Several features were extracted from the images using local binary patterns and histogram of oriented gradients method to identify the classification of sour lemons. The images were distinguished based on CNN models using stochastic pooling mechanism and data augmentation to improve the classification results. Gan et al. (2020) have explored the R-CNN method to detect immature fruit in citrus fruits with an overall classification accuracy of $96 \%$.

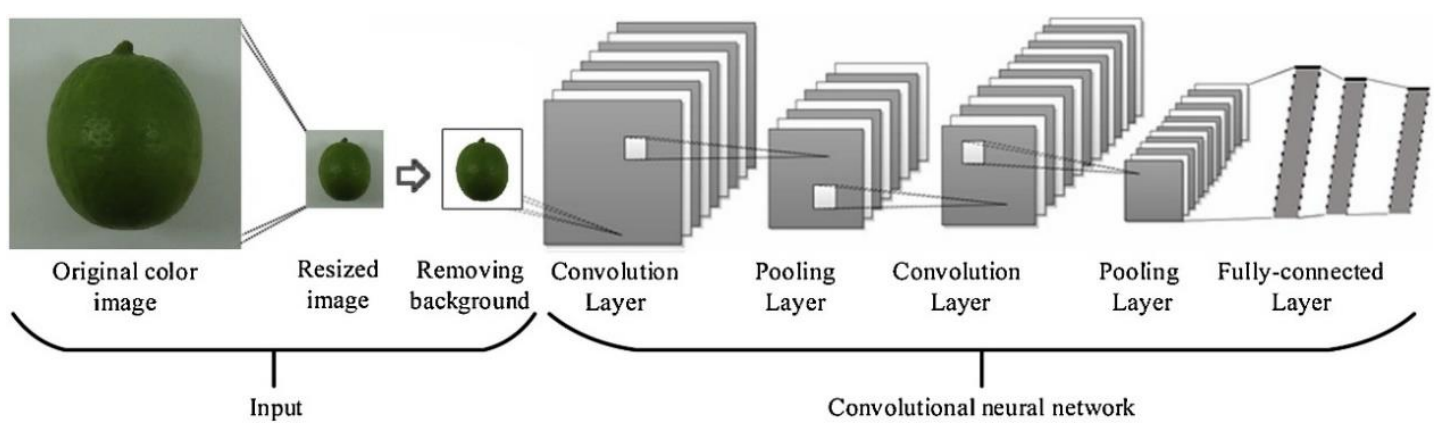

Figure 3. CNN architecture for the healthy and damaged classification of sour lemons (Jahanbakhshi et al., 2020).

In other work, Izquierdo et al. (2020) determined the adulteration of extra virgin olive oil during the cooling process. CNN models were developed to classify the samples according to the adulterant concentration with a classification accuracy of up to 97\%. Liu et al. (2020) designed CNN models for the identification of kiwifruits based on the near-infrared images 
with an overall accuracy of 90\%. Zhang et al. (2020) evaluated the chemical compositions of black goji berries using near-infrared hyperspectral imaging. The findings indicated a good performance of the CNN models compared to the conventional methods such as successive projection algorithm and partial least squares. Villaseñor-Aguilar et al. (2020) examined the maturity estimation of bell peppers using a fuzzy logic model. It was revealed that the fuzzy logic model obtained an accuracy of $99 \%$ in order to classify the maturity level of bell peppers. Osako et al. (2020) investigated the variety identification of litchi using CNN model, resulting in a classification accuracy of $84 \%$. Likewise, Chen and Yan (2020) evaluated the maturity estimation of fresh tea shoots using the CNN model. In the proposed method, the VGG-16 architecture was selected for the establishment of the CNN model which successfully classified the fresh tea with the testing dataset obtained accuracy of 0.68 .

Caladcad et al. (2020) studied the classification of coconuts according to the maturity levels using machine learning methods. Three machine learning tools were selected; ANN, SVM, and random forest for the maturity estimation of coconuts with an overall classification accuracy of up to $80 \%$. Cotrim et al. (2020) designed a CNN model to assess the browning degree of bread crust during baking. The findings showed that the CNN model gave correct prediction higher than $99 \%$ for all classes of browning degree of bread crust. Sadhu et al. (2020) determined the correlation between temperature, time, oil amount, and nutritional values of fried fish. The ANN model used had successfully tuned the cooking parameters to regain the nutritional composition of the fried fish. Guedes et al. (2020) measured the stalk content prediction of sugarcane using ANN model coupled with the colour information from the images. The study achieved relative errors of $3 \%$ by developing the ANN architecture using the average colour values (input layer) and the sugarcane stalk content (output layer) as shown in Figure 4. The ANN architecture was built using 10 neurons in input layer, 8 neurons in hidden layer, and 1 neuron in output layer associated with the sugar content in sugarcane stalks. It was revealed that ANN model offers the best prediction to obtain high quality of sugar content with correlation coefficients of 0.98 . The demand for high-quality food products is progressing tremendously in relation to the awareness and health concerns of consumers. Hence, the advancement of AI delivers an opportunity for the required tools to be readily accessible in monitoring the quality inspection of various food and agricultural products. 


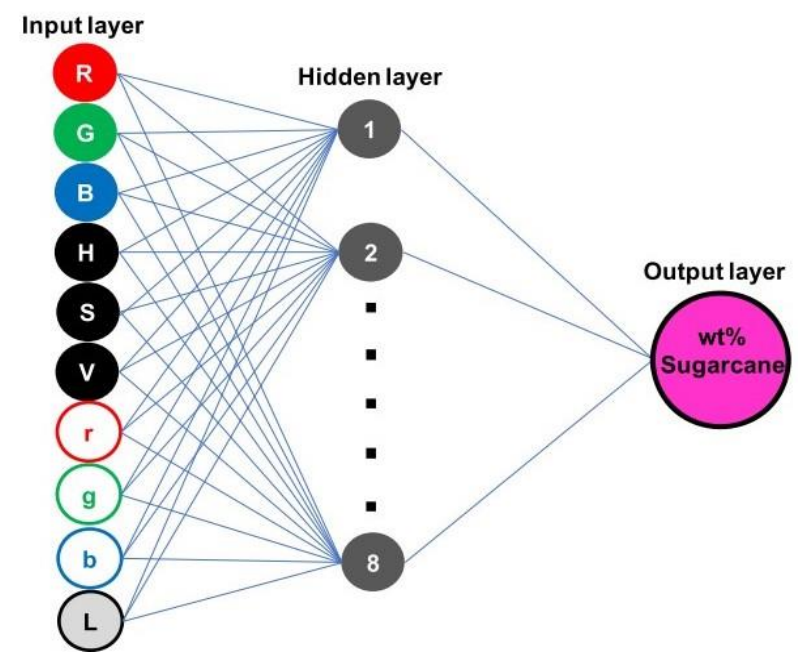

Figure 4. ANN architecture using the average colour values (input layer) and the sugarcane stalk content (output layer) (Guedes et al., 2020).

\section{Challenges and Future Trends}

Different AI applications for quality detection of food and agricultural products can be implemented through different forms including expert system, ANN, and fuzzy logic. The main idea of using these AI applications is to minimise human intervention and efforts. These methods have their own benefits and limitations in terms of theoretical knowledge and interpretation of model. Considering the differences of these AI tools, several hybrid nondestructive techniques such as electronic nose, computer vision system, and spectroscopic methods have been integrated for real-time monitoring in problem-solving related to food quality. Apart from that, the combinations of expert system, ANN, and fuzzy logic with mathematical models could increase the robustness and computational efficiency of the overall systems. It is worth mentioning that the emergence of advanced software and embedded control system based on AI could provide a key direction for scientific research in the future.

Even though expert system, ANN, and fuzzy logic are considered promising tools for quality detection of food and agricultural products, the development of AI still faces many challenges for it to be adopted in existing technologies. For instance, the major challenge of the development of ANN is in the adaptation of non-linear dynamic systems and neural network mathematical theories. Moreover, ANN is quite complex to interpret which involves the relationship between the selected variables as it does not offer actual information of weighting parameters. As for the expert system and fuzzy logic, the design and optimisation are the current issues that need to be solved considering there is no theoretical knowledge for the operational system. Nevertheless, the innovation of expert system, ANN, and fuzzy logic is very promising due to the advent of powerful algorithms and generalisation ability. With the rapid advances of cloud computing and big data, it can be foreseen that more research output can be generated for developing intelligent systems regarding food quality detection. 


\section{Conclusions}

AI is developing with rapid growth which can be implemented to perform quality inspection of various food and agricultural products. Numerous integrated applications have been created in order to provide a viable platform for the assessment of food quality. Despite the requirement for an extensive data modelling task, the arrival of decision support tools could pave a way to assist in the quality inspection of food and agricultural products. In order to support the decision-making using the applications in AI systems, a user-friendly approach is initiated to perform computational models for the related tasks involving forecasting the food quality. Considering the different AI-driven techniques, the efficiency of available tools can also be improved with the aid of scientific approaches in food quality inspection. Expert system, ANN, and fuzzy logic are certain domains in AI which enhance the process of problem-solving. Among all of these domains, ANN is the most widely applied for research purposes as it delivers high precision in terms of accuracy and rapid observation for the quality detection of food and agricultural products. Apart from that, the advances in image recognition software and AI data analytic tools can solve the problems encompassing the lack of labour skills and tedious routine analysis. Therefore, the use of AI in the quality inspection of food and agricultural products provides the advantages of convenient operation as well as to improve productivity in the food-related areas and supply chain.

Author Contributions: Conceptualization, N.H. and O.L.; methodology, M.M.A.; software, M.M.A.; validation, S.A.A.; formal analysis, S.A.A.; investigation, M.M.A.; resources, N.H. and O.L.; data curation, M.M.A.; writing-original draft preparation, M.M.A.; writing-review and editing, M.M.A. and N.H.

Funding: This work was funded by the Putra Grant, GP-IPB (Project code: GP-IPB/2020/9687800).

Acknowledgments: The authors would like to acknowledge the valuable support from the Department of Biological and Agricultural Engineering, Faculty of Engineering, Universiti Putra Malaysia for providing the technical facilities used in this research.

Conflicts of Interest: The authors declare no conflict of interest.

\section{References}

Al-Sarayreh, M., Reis, M. M., Yan, W. Q., et al. (2018). Detection of Red-Meat Adulteration by Deep SpectralSpatial Features in Hyperspectral Images. Journal of Imaging, 4(63), 1-20. https://doi.org/10.3390/jimaging4050063

Anderson, N. T., Walsh, K. B., Flynn, J. R., et al. (2021). Achieving robustness across season, location and cultivar for a NIRS model for intact mango fruit dry matter content. II. Local PLS and nonlinear models. Postharvest Biology and Technology, 171, 1-12. https://doi.org/10.1016/j.postharvbio.2020.111358

Azarmdel, H., Jahanbakhshi, A., Mohtasebi, S. S., et al. (2020). Evaluation of image processing technique as an expert system in mulberry fruit grading based on ripeness level using artificial neural networks (ANNs) and support vector machine (SVM). Postharvest Biology and Technology, 166, 1-12. https://doi.org/10.1016/j.postharvbio.2020.111201

Bai, Y., Xiong, Y., Huang, J., et al. (2019). Accurate prediction of soluble solid content of apples from multiple geographical regions by combining deep learning with spectral fingerprint features. Postharvest Biology 
and Technology, 156, 1-9. https://doi.org/10.1016/j.postharvbio.2019.110943

Bresilla, K., Perulli, G. D., Boini, A., et al. (2019). Single-shot convolution neural networks for real-time fruit detection within the tree. Frontiers in Plant Science, 10, 1-12. https://doi.org/10.3389/fpls.2019.00611

Caladcad, J. A., Cabahug, S., Catamco, M. R., et al. (2020). Determining Philippine coconut maturity level using machine learning algorithms based on acoustic signal. Computers and Electronics in Agriculture, 172, 105327. https://doi.org/10.1016/j.compag.2020.105327

Castro, W., Oblitas, J., De-La-Torre, M., et al. (2019). Classification of Cape Gooseberry Fruit According to its Level of Ripeness Using Machine Learning Techniques and Different Color Spaces. IEEE Access, 7, 27389-27400. https://doi.org/10.1109/ACCESS.2019.2898223

Chen, B., Yan, J. (2020). Fresh Tea Shoot Maturity Estimation via Multispectral Imaging and Deep Label Distribution Learning. IEICE Transactions on Information and Systems, E103.D(9), 2019-2022. https://doi.org/10.1587/transinf.2020ed18038

Cheng, J. H., Sun, D. W. (2015). Recent Applications of Spectroscopic and Hyperspectral Imaging Techniques with Chemometric Analysis for Rapid Inspection of Microbial Spoilage in Muscle Foods. Comprehensive Reviews in Food Science and Food Safety, 14(4), 478-490. https://doi.org/10.1111/1541-4337.12141

Cotrim, W. da S., Minim, V. P. R., Felix, L. B., et al. (2020). Short convolutional neural networks applied to the recognition of the browning stages of bread crust. Journal of Food Engineering, 277, 1-8. https://doi.org/10.1016/j.jfoodeng.2020.109916

Duong, L. T., Nguyen, P. T., Di Sipio, C., et al. (2020). Automated fruit recognition using EfficientNet and MixNet. Computers and Electronics in Agriculture, 171, 1-10. https://doi.org/10.1016/j.compag.2020.105326

Eli-Chukwu, N. C. (2019). Applications of Artificial Intelligence in Agriculture: A Review. Engineering Technology \& Applied Science Research, 9(4), 4377-4383.

Estrada-Pérez, L. V., Pradana-López, S., Pérez-Calabuig, A. M., et al. (2021). Thermal imaging of rice grains and flours to design convolutional systems to ensure quality and safety. Food Control, 121, 1-8. https://doi.org/10.1016/j.foodcont.2020.107572

Gan, H., Lee, W. S., Alchanatis, V., et al. (2020). Active thermal imaging for immature citrus fruit detection. Biosystems Engineering, 198, 291-303. https://doi.org/10.1016/j.biosystemseng.2020.08.015

Gonzalez, S., Arellano, C., Tapia, J. E. (2019). Deepblueberry: Quantification of Blueberries in the Wild Using Instance Segmentation. $\quad$ IEEE Access, $\quad 7, \quad$ 105776-105788. https://doi.org/10.1109/ACCESS.2019.2933062

Guedes, W. N., dos Santos, L. J., Filletti, É. R., et al. (2020). Sugarcane Stalk Content Prediction in the Presence of a Solid Impurity Using an Artificial Intelligence Method Focused on Sugar Manufacturing. Food Analytical Methods, 13(1), 140-144. https://doi.org/10.1007/s12161-019-01551-2 
Habaragamuwa, H., Ogawa, Y., Suzuki, T., et al. (2018). Detecting greenhouse strawberries (mature and immature), using deep convolutional neural network. Engineering in Agriculture, Environment and Food, 11(3), 127-138. https://doi.org/10.1016/j.eaef.2018.03.001

How, M. L., Chan, Y. J., Cheah, S. M. (2020). Predictive insights for improving the resilience of global food security using artificial intelligence. Sustainability (Switzerland), 12(6272), 1-14. https://doi.org/10.3390/SU12156272

Hussain, A., Pu, H., Sun, D. W. (2018). Innovative nondestructive imaging techniques for ripening and maturity of fruits - A review of recent applications. Trends in Food Science and Technology, 72, 144-152. https://doi.org/10.1016/j.tifs.2017.12.010

Ireri, D., Belal, E., Okinda, C., et al. (2019). A computer vision system for defect discrimination and grading in tomatoes using machine learning and image processing. Artificial Intelligence in Agriculture, 2, 28-37. https://doi.org/10.1016/j.aiia.2019.06.001

Izquierdo, M., Lastra-Mejías, M., González-Flores, E., et al. (2020). Deep thermal imaging to compute the adulteration state of extra virgin olive oil. Computers and Electronics in Agriculture, 171, 1-8. https://doi.org/10.1016/j.compag.2020.105290

Jahanbakhshi, A., Momeny, M., Mahmoudi, M., et al. (2020). Classification of sour lemons based on apparent defects using stochastic pooling mechanism in deep convolutional neural networks. Scientia Horticulturae, 263, 1-10. https://doi.org/10.1016/j.scienta.2019.109133

Jha, K., Doshi, A., Patel, P., et al. (2019). A comprehensive review on automation in agriculture using artificial intelligence. Artificial Intelligence in Agriculture, 2, 1-12. https://doi.org/10.1016/j.aiia.2019.05.004

Jhawar, J. (2016). Orange Sorting by Applying Pattern Recognition on Colour Image. Physics Procedia, 78(December 2015), 691-697. https://doi.org/10.1016/j.procs.2016.02.118

Kanade, A., Shaligram, A. (2018). Ripening state determination of guava fruit (Psidium guajava) using e-nose with fuzzy logic as pattern recognition tool. International Journal of Scientific Research Engineering \& Technology, 7(4), 362-367.

Kang, H., Chen, C. (2020). Fast implementation of real-time fruit detection in apple orchards using deep learning. Computers and Electronics in Agriculture, 168(November 2019), 105108. https://doi.org/10.1016/j.compag.2019.105108

Kumar, M. K., Kumar, R. S., Sankar, V., et al. (2017). Non-destructive estimation of leaf area of durian (Durio zibethinus) - An artificial neural network approach. Scientia Horticulturae, 219, 319-325. https://doi.org/10.1016/j.scienta.2017.03.028

Le, T. T., Lin, C. Y., Piedad, E. J. (2019). Deep learning for noninvasive classification of clustered horticultural crops - A case for banana fruit tiers. Postharvest Biology and Technology, 156, 1-10. https://doi.org/10.1016/j.postharvbio.2019.05.023 
Liu, J., Pi, J., Xia, L. (2019). A novel and high precision tomato maturity recognition algorithm based on multilevel deep residual network. Multimedia Tools and Applications, 1-15. https://doi.org/10.1007/s11042019-7648-7

Liu, Z., Wu, J., Fu, L., et al. (2020). Improved Kiwifruit Detection Using Pre-Trained VGG16 with RGB and NIR Information Fusion. IEEE Access, 8, 2327-2336. https://doi.org/10.1109/ACCESS.2019.2962513

Mishra, P., Nordon, A., Mohd Asaari, M. S., et al. (2019). Fusing spectral and textural information in nearinfrared hyperspectral imaging to improve green tea classification modelling. Journal of Food Engineering, 249, 40-47. https://doi.org/10.1016/j.jfoodeng.2019.01.009

Ortega, J. B., Gila, D. M. M., Puerto, D. A., et al. (2016). Novel technologies for monitoring the in-line quality of virgin olive oil during manufacturing and storage. Journal of The Science of Food and Agriculture, 96, 4644-4662. https://doi.org/10.1002/jsfa.7733

Osako, Y., Yamane, H., Lin, S. Y., et al. (2020). Cultivar discrimination of litchi fruit images using deep learning. Scientia Horticulturae, 269, 1-7. https://doi.org/10.1016/j.scienta.2020.109360

Qiu, Z., Chen, J., Zhao, Y., et al. (2018). Variety identification of single rice seed using hyperspectral imaging combined with convolutional neural network. Applied Sciences (Switzerland), 8(212), 1-12. https://doi.org/10.3390/app8020212

Rady, A., Guyer, D., Lu, R. (2015). Evaluation of Sugar Content of Potatoes using Hyperspectral Imaging. Food and Bioprocess Technology, 8, 995-1010. https://doi.org/10.1007/s11947-014-1461-0

Rodríguez, F. J., García, A., Pardo, P. J., et al. (2018). Study and classification of plum varieties using image analysis and deep learning techniques. Progress in Artificial Intelligence, 7(2), 119-127. https://doi.org/10.1007/s13748-017-0137-1

Sadeghi-Tehran, P., Virlet, N., Ampe, E. M., et al. (2019). DeepCount: In-Field Automatic Quantification of Wheat Spikes Using Simple Linear Iterative Clustering and Deep Convolutional Neural Networks. Frontiers in Plant Science, 10, 1-16. https://doi.org/10.3389/fpls.2019.01176

Sadhu, T., Banerjee, I., Lahiri, S. K., et al. (2020). Modeling and optimization of cooking process parameters to improve the nutritional profile of fried fish by robust hybrid artificial intelligence approach. Journal of Food Process Engineering, 43(9), 1-13. https://doi.org/10.1111/jfpe.13478

Sanaeifar, A., Jafari, A. (2019). Determination of the oxidative stability of olive oil using an integrated system based on dielectric spectroscopy and computer vision. Information Processing in Agriculture, 6(1), 2025. https://doi.org/10.1016/j.inpa.2018.08.008

Santos, T. T., de Souza, L. L., dos Santos, A. A., et al. (2020). Grape detection, segmentation, and tracking using deep neural networks and three-dimensional association. Computers and Electronics in Agriculture, 170, 105247. https://doi.org/10.1016/j.compag.2020.105247

Seka, D., Bonny, B. S., Yoboué, A. N., et al. (2019). Identification of maize (Zea mays L.) progeny genotypes 
based on two probabilistic approaches: Logistic regression and naïve Bayes. Artificial Intelligence in Agriculture, 1, 9-13. https://doi.org/10.1016/j.aiia.2019.03.001

Sharma, R., Kamble, S. S., Gunasekaran, A., et al. (2020). A systematic literature review on machine learning applications for sustainable agriculture supply chain performance. Computers and Operations Research, 119, 1-17. https://doi.org/10.1016/j.cor.2020.104926

Srivastava, S., Sadistap, S. (2018). Data processing approaches and strategies for non-destructive fruits quality inspection and authentication: a review. In Journal of Food Measurement and Characterization (Vol. 12, Issue 4). Springer US. https://doi.org/10.1007/s11694-018-9893-2

Suksawat, B., Komkum, P. (2015). Pineapple quality grading using image processing and fuzzy logic based on Thai Agriculture Standards. International Conference on Control, Automation and Robotics, 218-222. https://doi.org/10.1109/ICCAR.2015.7166035

Sun, Q., Zhang, M., Mujumdar, A. S. (2019). Recent developments of artificial intelligence in drying of fresh food: A review. Critical Reviews in Food Science and Nutrition, 59(14), 2258-2275. https://doi.org/10.1080/10408398.2018.1446900

Sun, Y., Lu, R., Lu, Y., et al. (2019). Detection of early decay in peaches by structured-illumination reflectance imaging. Postharvest Biology and Technology, 151, 68-78. https://doi.org/10.1016/j.postharvbio.2019.01.011

Sunarya, P. A., Mutiara, A. B., Refianti, R., et al. (2019). Identification of guava fruit maturity using deep learning with convolutional neural network method. Journal of Theoretical and Applied Information Technology, 97(19), 5126-5137.

Talaviya, T., Shah, D., Patel, N., et al. (2020). Implementation of artificial intelligence in agriculture for optimisation of irrigation and application of pesticides and herbicides. Artificial Intelligence in Agriculture, 4, 58-73. https://doi.org/10.1016/j.aiia.2020.04.002

Venugopal, V., Gopakumar, K. (2017). Shellfish: Nutritive Value, Health Benefits, and Consumer Safety. Comprehensive Reviews in Food Science and Food Safety, 16(6), 1219-1242. https://doi.org/10.1111/1541-4337.12312

Villaseñor-Aguilar, M. J., Bravo-Sánchez, M. G., Padilla-Medina, J. A., et al. (2020). A maturity estimation of bell pepper (Capsicum annuum L.) by artificial vision system for quality control. Applied Sciences (Switzerland), 10(5097), 1-18. https://doi.org/10.3390/app10155097

Zhang, C., Wu, W., Zhou, L., et al. (2020). Developing deep learning based regression approaches for determination of chemical compositions in dry black goji berries (Lycium ruthenicum Murr.) using nearinfrared hyperspectral imaging. Food Chemistry, 319, 1-9. https://doi.org/10.1016/j.foodchem.2020.126536

Zhou, L., Zhang, C., Liu, F., et al. (2019). Application of Deep Learning in Food: A Review. Comprehensive Reviews in Food Science and Food Safety, 18(6), 1793-1811. https://doi.org/10.1111/1541-4337.12492 
Copyright $(92021$ by Mohd Ali, M. et al. and HH Publisher. This work is licensed under the Creative 